\title{
Effect of $\mathrm{MgCl}_{2}$ and $\mathrm{CaCl}_{2}$ on the Bubble Point of Mixed-Solvents [Toluene-Isopropyl Alcohol-H ${ }_{2} \mathrm{O}$ System]
}

\author{
Nathaniel P. Dugos \\ Department of Chemical Engineering \\ Adamson University, Manila, Philippines \\ Noel P. Cabigon \\ MACCH Management and Consultancy Corp. \\ Manila, Philippines \\ Yolanda P. Brondial \\ Department of Chemical Engineering \\ De La Salle University, Manila, Philippines
}

\begin{abstract}
This study investigated the effect of $\mathrm{CaCl}_{2}$ and $\mathrm{MgCl}_{2}$, both alkaline earth metal salts on the boiling points of a mixed-solvent system composed of toluene, isopropyl alcohol and water. The effect of the concentration of the salt on the boiling point of this ternary system was also examined. Results showed that mixed- solvents added with $\mathrm{CaCl}_{2}$ boil at higher temperatures than those with $\mathrm{MgCl}_{2}$ even though the latter salt is higher in molal concentration. This proves that $\mathrm{MgCl}_{2}$, which has a smaller ionic radius than $\mathrm{CaCl}_{2}$ is more effective in reducing the molecular affinity to polar and associating solvents (water and isopropyl alcohol) than to the non-polar solvent (toluene). The mixed- solvent system added with $\mathrm{MgCl}_{2}$ registered higher boiling point deviation than those with $\mathrm{CaCl}_{2}$, though both showed positive deviations. Based on the results, either of the two salts can be an effective mass separating agent. However it is shown that $\mathrm{MgCl}_{2}$ is better than $\mathrm{CaCl}_{2}$ because the solutions with $\mathrm{MgCl}_{2}$ generally exhibited lower boiling points. Though the difference in temperature deviations of the two salts is statistically not significant, a difference in temperature of one degree is economically significant considering the cost of energy.
\end{abstract}

Keywords. bubble point, azeotrope, salt effect, molecular affinity

\section{INTRODUCTION}

Semiconductor, optical and related industries are the progressive industries in the Philippines. They are at the forefront of the technological advancement. These industries contribute about $75 \%$ of the country's export and generate thousands of jobs for Filipinos nationwide. This is the reason why the government has created several export processing zones. Indeed, these industries help the country in improving its economy. However, it cannot be denied that they contribute significant amount of hazardous wastes among which are the spent organic solvents.

Organic solvents are commonly used in cleaning microchips, electronic devices and gadgets, machines and other process equipment 
or elements to remove dirt, grease, adhering moisture, etc. Hence the industrial sector generates large amounts of spent solvents. These waste solvents contain as high as $90 \%$ of valuable organic solvents such as isopropyl alcohol, acetone, ethyl acetate, methylethyl ketone, ethanol and toluene. Philippine industries generate about 12,000 metric tons of spent solvents annually and this volume is continuously increasing. At this quantity, solvent recovery is a viable option. These organic solvents are hazardous and some are carcinogenic. By recovering part or most of the valuable organic solvents present in the spent solvents, the amount to be disposed of or treated will be substantially reduced. As a result it will also minimize the hazards that the spent solvents may pose to humans and the damage that it may cause to the environment. And for the industry, productivity will be improved by substantial reduction in operating cost and increased savings and income derived from the recovered solvents.

Separation of mixed solvents is traditionally done by distillation. However there is a problem in recovering solvents of high purity due to the formation of azeotropes. Using traditional distillation for these types of solvent mixtures require further purification.

This work investigated the effects of the halide salts of $\mathrm{Ca}$ and $\mathrm{Mg}$ on the bubble points of a mixture of isopropyl alcohol, toluene and water. Examined were the bubble point variations in the presence of the salts that can lead to effective separation by averting azeotropic state. Also evaluated are the differences in the bubble points of the two salts and which salt gives a larger deviation from Raoult's law. A large deviation would mean a shorter distillation tower.

The bubble point comparison helps in setting the criteria for the economic viability of the technology and in setting the options for its implementation. Though the research has been expanded to several types of solvent systems, this paper will present only the mixture of toluene, isopropyl alcohol and water.

\section{THEORY}

Current advances in molecular solution thermodynamics make it possible to separate selectively mixtures of compounds forming multiple azeotropes by conventional distillation One method is to reduce the molecular attractions among the species in solution by introducing a compound (or mass separating agent) that has greater molecular affinity to the species other than the one to be separated. The method has successfully worked for many binary systems.

In this study, the method is applied to a ternary system composed of toluene, isopropyl alcohol (IPA) and water. The technique involves the addition of an alkaline earth metal salt of onecation-and-two-anion type. The salt serves as the mass separating agent whose purpose is to alter the affinity of the systems water-IPA and IPAtoluene. At equilibrium, several intermolecular forces exist among the five interacting species in solution. The species include the solvents, the cation and anion from the ionized salt and the unionized salt. The intermolecular interactions that maybe present among these species are dipole-dipole, hydrogen bonds, ion-dipole, dispersion forces etc. and the magnitude of these forces vary depending on the nature of the species present and their concentration.

$\mathrm{MgCl}_{2}$ and $\mathrm{CaCl}_{2}$, halide salts of Group IIA are considered strong salts. With complete ionization the total ion concentration is three times the molal concentration of the salt as shown below:

$$
\begin{aligned}
& \mathrm{MgCl}_{2} \rightarrow \mathrm{Mg}^{++}+2 \mathrm{Cl}^{-} \\
& \mathrm{CaCl}_{2} \rightarrow \mathrm{Ca}^{++}+2 \mathrm{Cl}^{-}
\end{aligned}
$$

This suggests that the maximum boiling point rise (BPR) is expected to be three times the equivalent rise in BPR of a molal concentration of the salt.

Since the salt has high affinity towards water, its presence causes the lowering of the vapor pressure of water by the formation of an iondipole effect between the water molecules and the salt. In a limited amount, most of the salt will be attracted to the more polar substance. In this case, water is more polar than IPA. Toluene, which is non-polar, has no affinity towards the salt. Addition of the salt induces separation between the non-polar and polar solvents. Thus, the presence of the salt reduces the affinity of toluene to isopropyl alcohol. As the amount of salt is increased, the salt will reduce the vapor pressure not only of water but also of isopropyl 
alcohol. Thus, this effect will favor the release of more toluene into the vapor phase.

At a certain IPA concentration, the system starts to form two phases. The upper phase is toluene with dissolved IPA while the lower phase is water with dissolved IPA. IPA is distributed between two immiscible fluids such that at equilibrium the following Nernst Distribution Equation holds

$$
K=\frac{[I P A]_{\text {toluene }}}{[I P A]_{\mathrm{H}_{2} \mathrm{O}}}
$$

where $\mathrm{K}$ is the Nernst distribution constant and the chemical potential of IPA in the two phases are equal. The presence of a strong salt, such as $\mathrm{CaCl}_{2}$, changes the value of $\mathrm{K}$ at a given temperature, which in turn affect the boiling point profile of the mixture.

Upon the addition of salt, the chemical potential of the aqueous layer will increase hence the equilibrium will shift towards the toluene layer. This means, part of IPA will transfer to the toluene layer. The amount of IPA that will transfer is dependent on the chemical potential at the new equilibrium. The new equilibrium would have layers with different IPA concentrations from the former. The shift is due to the strong molecular attraction of the salt to water and practically no attraction to toluene. Thus in the IPA-toluenewater system part of IPA is expelled from the water layer and goes to the toluene layer resulting in an increased value of $\mathrm{K}$ (equation 1 ).

The overall effect of the molecular interaction explains the thermodynamic deviation of the mixture from ideal solutions. In theory, there are three possible significant molecular interactions that can be accounted for but these are often difficult or expensive to measure experimentally. They are usually determined using secondary data and extended UNIQUAC (Universal Quasi Chemical model) method or some other measurements such as osmotic property of solutions with ionic species for the chemical potential estimation of the electrolytes.

Molecular interactions account for the deviations of the thermodynamic properties of the system. The deviations are due to combinatorial $\left(G^{c}\right.$, i.e., due to collision between two or more molecules); residual ( $G^{R}$, i.e., due to size and shape of the molecules), and electrostatic $\left(G^{E}\right.$, i.e., due to attraction and repulsion of charge particles) effects. There may be other factors responsible for the deviation in property of the solution but they are assumed to be insignificant compared to these three. Thus the extended UNIQUAC equation of the excess Gibbs property of the solution can be written as the sum of the three molecular interactions (equation 2).

$$
G=G^{C}+G^{R}+G^{E}
$$

These molecular interactions affect the thermodynamic properties of the solution. This explains the deviation of the vapor-liquid equilibrium behavior from Raoult's Law. To account for these interactions, a modified Raoult's law was developed where it assumes that the gas and liquid phases in equilibrium are real. The generalized equation where the vapor and liquid form real fluids is presented in Equation 3:

$$
\sum_{1}^{k} y_{j i} \hat{\phi}_{j i} P=\sum_{1}^{k} \sum_{1}^{n} x_{j i} \gamma_{j i} P_{i}^{s a t}
$$

For systems that will form two liquid phases in equilibrium the equation is presented in Equation 2.

$$
\left(\sum_{i=1}^{k} x_{i} \gamma_{i} P_{i}^{s a t}\right)_{\alpha}+\left(\sum_{i=1}^{k} x_{i} \gamma_{i} P_{i}^{s a t}\right)_{\beta}=\sum_{1}^{k} y_{i} \Phi_{i} P
$$

where $\mathrm{i}, \mathrm{j}=1,2,3, \mathrm{k}$ or $\mathrm{n}$

The subscript $i$ refer to the species in phase $j$. Equation 4 is for systems forming two liquid phases $a$ and $b$ that are completely immiscible with each other. When the sum of the pressures exerted by the two phases is equal to the confining pressure the mixture boils. Hence, the boiling point of the mixture is lower than those of the two phases. This equation is applicable to all types of systems even in the presence of electrolytes. The value of $\mathrm{g}$ is approximated using the mean ionic activity coefficient $\left(\gamma^{ \pm}\right)$. It depends on the nature of the species, the type of molecular interaction and within molecule group 
contribution. The symbol $\mathrm{f}$ is the fugacity coefficient. Parameters $f$ and $g$ can be calculated using UNIQUAC and NRTL for non-electrolytes and extended UNIQUAC method for electrolytes.

During a typical distillation the chemical potential of the constituents of the feed solution changes as the most volatile component concentrates in the vapor phase while the least volatile one remains in the liquid phase. As separation progresses, a point is reached wherein the concentrations of the species in the liquid and vapor phases in equilibrium are equal. At this state (azeotropic point) the solution can no longer be separated due to the formation of a relatively stable intermolecular interaction. If the azeotropic condition is broken or averted, then the separation of the components in equilibrium is possible.

\section{METHODOLOGY}

The research was divided into two phases. The first was the design of the experiment. The full block model was used with three levels based on solubility of the salts at room temperature. The salt levels were unsaturated $(10 \mathrm{~g} / \mathrm{L}$ or $0.11-0.12$ molal), saturated $(0.32$ to $0.68 \mathrm{~m})$ and supersaturated $(85 \mathrm{~g} / \mathrm{L}$ or 0.91 to $1.06 \mathrm{molal})$. The parameters tested were (1) the effect of the amount of salt on the boiling point; (2) the no. of phases at different mole fraction of the solvents in the solution; and (3) the comparison of the effects of $\mathrm{CaCl}_{2}$ and $\mathrm{MgCl}_{2}$ on the boiling points of the mixed solvents. The amount of water was fixed while those of toluene and isopropyl alcohol were varied.

The second phase was the experimental part, which was further divided into two: one was the boiling point determination of the different mixtures of IPA-toluene-water in the presence of $\mathrm{MgCl}_{2}$ and the other in the presence of $\mathrm{CaCl}_{2}$.

Mixtures of IPA-toluene-water were prepared in different mole ratios. Each mixture was then divided into four portions. Different amounts of the salt were added to three of these solutions. The first simulated the unsaturated solution of salt; the second corresponds to the saturated solution at near boiling; while the third simulated the supersaturated solution at the boiling point. The fourth fraction, which was left salt-free, served as the control. These variations were used to determine how the boiling point behaved under multiple phase condition. The solutions were then refluxed to determine the boiling points.

\section{RESULTS AND DISCUSSION}

The boiling point profiles of the mixture without salt are presented in Figure 1. It can be observed that at a certain composition range two phases exist. This shows that at these compositions neither of the two organic solvents could serve as solvent for the other based on their mutual solubility with each other. The two phases occur when the mole concentration of isopropyl alcohol (IPA) is about $18 \%$ to $60 \%$ which forms an envelope as shown in Fig.1. These phases arise when toluene and water are both saturated with IPA. The upper layer is toluene-IPA system while the lower layer is water-IPA. Similar but more pronounced separation is observed when salts are added.

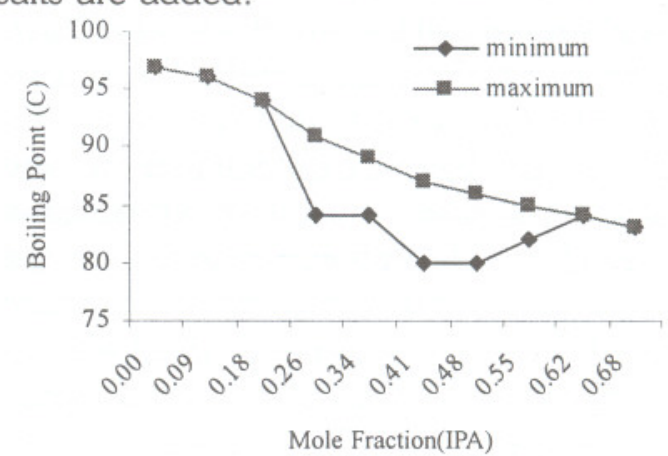

Figure1. Boiling point profile of mixed- solvents without salt.

Figure 2 presents boiling point profiles that show the effect of the concentration of the salt on the boiling point of the system. It illustrates that the addition of salts allows more toluene to escape into the vapor phase (i.e., by decreasing the vapor pressure of both water and IPA). When a small amount of salt, $10 \mathrm{~g}$ salt per liter (around 0.110.12 molal) of solution is added, the decrease in boiling point is lesser. Results showed that mixed solvents with $\mathrm{CaCl}_{2}$ boil at higher temperatures than those with $\mathrm{MgCl}_{2}$, even though the molal concentration of the latter is higher. Based on the result, the solvent mixture with $\mathrm{MgCl}_{2}$ showed more of the effect of molecular affinity, while the mixture with $\mathrm{CaCl}_{2}$ manifests more of the colligative effect. This proves that $\mathrm{MgCl}_{2}$ with ionic 
size smaller than $\mathrm{CaCl}_{2}$ is more effective in reducing the molecular affinity to polar and associating solvents (water and isopropyl alcohol) than to non-polar solvent (toluene). Because of the smaller size of the magnesium ion it is able to hold or attract more water molecules to it than the calcium ion

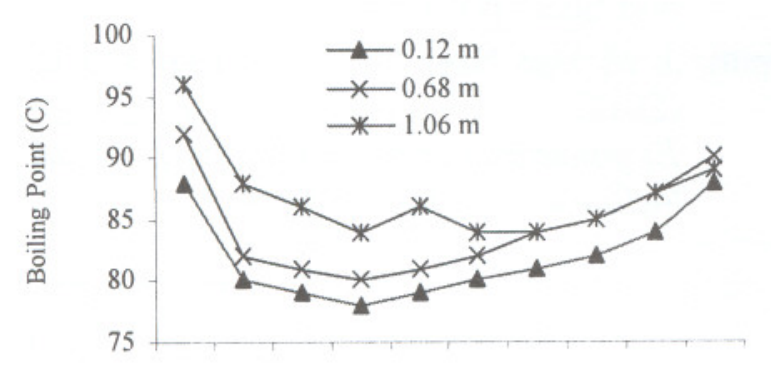

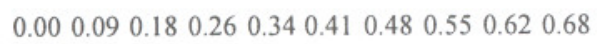

Mole Fraction(IPA)

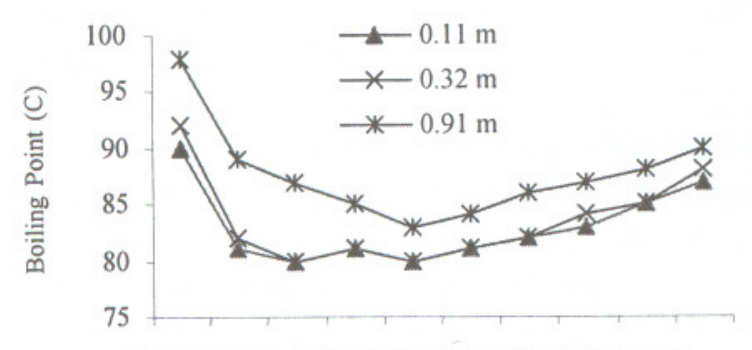

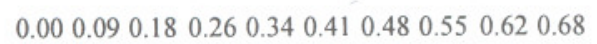

Mole Fraction(IPA)

Shown in Figure 3 is a comparison of the boiling point profiles of the two salts. At the lower concentration range where their relative molal concentrations are almost equal, the mixedsolvent with $\mathrm{MgCl}_{2}$ registered lower boiling points in most cases, although more $\mathrm{MgCl}_{2}$ is present. This is even more apparent when $85 \mathrm{~g} / \mathrm{L}$ salt is added. This amount is equivalent to around 1.06 $\mathrm{m} \mathrm{MgCl}_{2}$ and $0.91 \mathrm{~m} \mathrm{CaCl}_{2}$. Though, statistically these are not significantly different, a small difference in temperature may mean a substantial energy saving.

A statistical comparison is made also on the effect of increasing the amount of salt on the bubble point. It is evident that increasing the amount of salt increases the boiling point. Theoretically, one would expect that as more salt is added more water and IPA will be held back in the lower (water) layer. If this is the case then the boiling point should go down further. However, with more salt added the colligative effect starts to dominate. Beyond $0.32 \mathrm{~m}$ concentration of the salt, the boiling point of the solutions rose sharply indicating that the colligative effect became dominant to both salts.

Compared to ideal solutions (i.e., solutions behaving according to Raoult's Law), the mixed solvents added with $\mathrm{MgCl}_{2}$ registered higher boiling point deviation than those with $\mathrm{CaCl}_{2}$. The deviation is more pronounced at the supersaturated level but this is not statistically
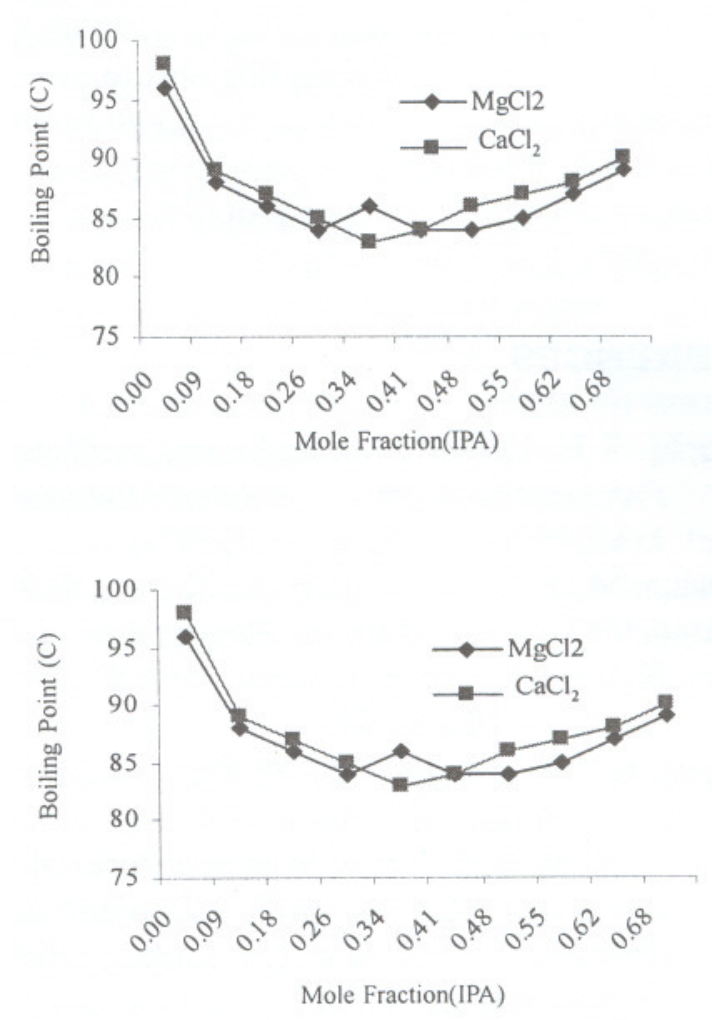

Figure 3. The graph on the left shows the boiling point profile of mixed solvents with of $1.06 \mathrm{~m} \mathrm{MgCl}_{2}$ and $0.91 \mathrm{~m} \mathrm{CaCl}_{2}$. The graph on the right is the plot of $0.12 \mathrm{~m} \mathrm{MgCl}$ and $0.11 \mathrm{~m} \mathrm{CaCl}_{2}$.

significant when the two results are compared numerically. However, a one degree temperature difference could mean a substantial saving in energy cost considering the amount of spent solvents to be separated. The observation also implies that a shorter distillation tower can be used to effectively separate the solvents; hence, lower capital investment costs. 
This finding is economically interesting because $\mathrm{MgCl}_{2}$ is relatively cheap and can be easily regenerated for reuse. Also, the mixed solvents can be distilled at lower temperature implying lower energy costs. This innovative separation technique will greatly benefit the semiconductor and all other industries generating spent solvents. The benefits include decreased volume of spent solvents to be stockpiled, savings from the waste handling costs and income derived from the recovered solvents.

\section{CONCLUSIONS}

$\mathrm{MgCl}_{2}$ is more effective than $\mathrm{CaCl}_{2}$ in modifying the molecular affinity between IPA and toluene system and in reducing the vapor pressure of water and IPA. It has a greater capability to lower the boiling point of the mixed-solvent (IPA-toluenewater) system than $\mathrm{CaCl}_{2}$.

\section{REFERENCES}

Bader, M. S. H. (1999) Thermodynamics of Ions Precipitation in Mixed-Solvent Mixtures, J. of Hazardous Materials B69 319-334.

Nagvekar, M., F. Tihminlioglu F. and Danner R.P. (1997) Colligative Properties of Polyelectrolyte Solutions, Fluid Phase Equilibria 145 15-41.

Cabigon, N.P. and Dugos N.P. (2003) " Bubble Point of Ternary Mixed-Solvents with Alkali Salts (Toluene- Isopropyl AlcoholWater - $\mathrm{NaCl}$ System)" Journal of Research in Science, Computing and Engineering Vol 2 No.1

Dugos, N.P. and Cabigon N.P. (2002) “ Separation of Ternary Mixed Solvents (IPA- TolueneWater System)", Proc. Chemical Engineering Congress 2002

Elliot, R.J. and Lira C.T. (1999). Introductory Chemical Engineering Thermodynamics, Prentice Hall International Series, NJ USA

Iliuta, M. C., Thomsen K. and Rasmussen P. (1999) Extended UNIQUAC Model for Correlation and Prediction of VaporLiquid-Solid Equilibria in Aqueous Salt System Containing Non-electrolytes. Part A. Methanol-Water-Salt Systems,
Chemical Engineering Science, 55, 26732686.

Laidler, Keith J. and Meiser J.H. (1999). Physical Chemistry $3^{\text {rd }}$ ed. Houghton Mifflin Company, Boston USA

Meyers Raymond H. and Montgomery D.C. (2002). Response Surface Methodology (Process and Product Optimization Using Designed Experiments) $2^{\text {nd }}$ ed. John Wiley and Sons, NY USA

Smith, J. M.,Van Ness H.C. and Abbot M.M. (2002). Introduction to Chemical Engineering Thermodynamics, $6^{\text {th }}$ ed. McGraw- Hill, Inc., New York 